\title{
Biophysical description of multiple events contributing blood leukocyte arrest on endothelium
}

\author{
Philippe Robert ${ }^{1,2,3,4}$, Dominique Touchard ${ }^{1,2,3}$, Pierre Bongrand $^{1,2,3,4}$ * and Anne Pierres ${ }^{1,2,3}$ \\ 1 Laboratoire Adhésion and Inflammation, Aix-Marseille Université, Marseille, France \\ 2 Institut National de la Santé et de la Recherche Médicale, Marseille, France \\ ${ }^{3}$ Centre National de la Recherche Scientifique, Marseille, France \\ ${ }^{4}$ Laboratoire d'Immunologie, Hôpitaux de Marseille, Hôpital de la Conception, Marseille, France
}

\section{Edited by:}

Klaus Ley, La Jolla Institute for Allergy and Immunology, USA

\section{Reviewed by:}

Alexander Zarbock, University of Muenster, Germany

Craig T. Lefort, La Jolla Institute for

Allergy and Immunology, USA

\section{*Correspondence:}

Pierre Bongrand, Laboratoire

Adhésion et Inflammation, INSERM U1067, Parc Scientifique de Luminy, Case 937, 13288 Marseille Cedex 09, France.

e-mail: pierre.bongrand@inserm.fr
Blood leukocytes have a remarkable capacity to bind to and stop on specific blood vessel areas. Many studies have disclosed a key role of integrin structural changes following the interaction of rolling leukocytes with surface-bound chemoattractants. However, the functional significance of structural data and mechanisms of cell arrest are incompletely understood. Recent experiments revealed the unexpected complexity of several key steps of cell-surface interaction: (i) ligand-receptor binding requires a minimum amount of time to proceed and this is influenced by forces. (ii) Also, molecular interactions at interfaces are not fully accounted for by the interaction properties of soluble molecules. (iii) Cell arrest depends on nanoscale topography and mechanical properties of the cell membrane, and these properties are highly dynamic. Here, we summarize these results and we discuss their relevance to recent functional studies of integrin-receptor association in cells from a patient with type III leukocyte adhesion deficiency. It is concluded that an accurate understanding of all physical events listed in this review is needed to unravel the precise role of the multiple molecules and biochemical pathway involved in arrest triggering.

Keywords: adhesion, ligand-receptor interaction, bond strength, integrin, clustering, avidity, dynamics, LAD-III

\section{INTRODUCTION}

Immune cells such as lymphocytes or phagocytes can bind to specific blood vessel areas and further migrate toward peripheral tissues. This allows memory lymphocyte patrolling throughout the organism to detect invading foreign material. Also, this allows endothelial cells of inflamed areas to trigger the arrest of blood leukocytes that are flowing in a resting state. Basic mechanisms have been elucidated during the early nineties (Lawrence and Springer, 1991; von Andrian et al., 1991; Springer, 1994), leading to a general paradigm that remains valid (Ley et al., 2007): leukocytes move with a velocity of several millimeters/second imposed by the blood flow (Atherton and Born, 1972). The earliest event is cell-surface tethering by specialized membrane receptors (Lawrence and Springer, 1994) such as P-selectin (CD62-P) on stimulated endothelial cells or L-selectin that is concentrated on the tip of leukocyte microvilli. Cells then display a somewhat jerky displacement $\left(5-10 \mu \mathrm{m} \mathrm{s}^{-1}\right)$ called rolling. This is due to the rapid formation and dissociation of bonds such as are formed between endothelial E- and P-selectins and lymphocyte-associated ligands comprising P-selectin glycoprotein ligand 1 (PSGL-1), E-selectin ligand 1 (ESL-1), and the hyaluronan receptor CD44 (Hidalgo et al., 2007). Tethering and rolling may also be driven by the interaction between vascular cell adhesion molecule 1 (VCAM1) expressed on properly stimulated endothelial cells and $\alpha 4 \beta 1$ (VLA-4, CD29dCD49) expressed on some leukocyte populations (Alon et al., 1995). A key property of bonds mediating rolling is their capacity to resist hydrodynamic forces of several tens of piconewtons for several tenths of a second (Evans et al., 2001,
2004). Rolling does not require any active cell participation since it may be reproduced with fixed cells (Lawrence and Springer, 1993) or with cell-free systems (Brunk et al., 1996). A likely explanation of rolling jerkiness is that at a given time a leukocyte is bound by a few or even a single bond and each bond rupture event results in a discrete forward displacement. Indeed, rolling velocity is strongly correlated to the bond dissociation rate (Alon et al., 1997).

The initial step of rapid rolling may be followed by an intermediate phase of "slow rolling" with more than twofold velocity decrease. This may result from a partial activation of lymphocyte function associated 1 integrin (LFA-1, CD11aCD18) enabling it to interact with intercellular cell adhesion molecule 1 (ICAM-1, CD54) expressed by endothelial cells (Jung et al., 1998). LFA-1 activation may be induced by E-selectin interaction with PSGL-1 (Kuwano et al., 2010) or CD44 (Yago et al., 2010).

Other phenomena were found to contribute the following arrest phase: the pulling force applied on cell-surface receptors may generate membrane tubes of up to $40 \mu \mathrm{m}$ length (Schmidtke and Diamond, 2000), thus decreasing the force applied on bonds as explained below. Also, it was recently shown that the tethers formed on neutrophils could wrap around rolling cells and display a "stepwise peeling" through patches of PSGL-1 molecules interacting with substrate P-selectin (Sundd et al., 2012). The authors suggested that this particular behavior might be responsible for the neutrophil capacity to roll at extremely high shear rates.

Arrest is mainly triggered by the complete activation of leukocyte integrins such as LFA-1 or VLA-4, enabling them to firmly bind endothelial ligands such as ICAM-1 or VCAM-1 respectively, 
as reviewed in this research topic (Chigaev and Sklar, 2012; Lefort and Ley, 2012). Subsecond integrin activation (Grabovksy et al., 2000; Alon and Dustin, 2007) is triggered by endothelium-bound chemoattractants that often belong to the chemokine family (Zlotnik and Yoshie, 2012). Thus, the same receptor family may be involved in directing cell locomotion and triggering arrest under shear flow (Campbell et al., 1998). The specificity of leukocyte species and arrest location is imparted by a particular combination of chemokines, adhesion molecules, and stimulation pathway (Rot and von Andrian, 2004). Following arrest, leukocytes may start crawling toward endothelial junctions and transmigrate toward surrounding tissues (Schenkel et al., 2004).

A current challenge is to understand the role of all involved molecules and signaling pathways. Here we shall describe the elementary physical events contributing the transition from rolling motion to LFA-1-mediated firm arrest. Indeed, a detailed understanding of physical constraints should help us understand the rationale of all cell processes contributing arrest. General concepts will be illustrated by addressing a specific problem: relating kindlin-3 deficiency to functional defects in LAD-III patients.

A prerequisite for assessing the use and significance of elementary events such as integrin clustering or membrane topographical reorganization is to build a quantitative scheme of the arrest phenomenon as a physical process.

\section{PHYSICAL BACKGROUND}

To estimate the intensity and effect of forces applied on leukocytes under flow, we need a simple model of cells as physical objects.

\section{MECHANICAL AND GEOMETRICAL PROPERTIES OF BLOOD LEUKOCYTES}

Micrometer-scale leukocyte rheological properties were studied by monitoring the deformation of cells sucked into micropipettes with controlled pressure (Evans and Yeung, 1989). Neutrophils behaved as viscous liquid spherical droplets (about $10^{-5}$ Pa.s viscosity and $8 \mu \mathrm{m}$ diameter) surrounded by a membrane under tension $\left(\sim 3.5 \times 10^{-5} \mathrm{~N} \mathrm{~m}^{-1}\right)$. This is a minimal model (Herant et al., 2003). First, cells are composite objects. Thus, nuclear and cytoplasmic properties may be widely different. Secondly, applying mechanical forces may initiate active mechanical responses (Horoyan et al., 1990). However, this model may be relevant to the initial phase of leukocyte arrest under flow.

The structural basis of cell mechanical properties was studied with electron microscopy. Leukocytes are surrounded by a fairly inextensible lipid bilayer with numerous folds appearing as finger-like structures called microvilli or ridge-like folds (Bruehl et al., 1996; Shao et al., 1998). The average length is $\sim 0.3 \mu \mathrm{m}$ and diameter or thickness is $\sim 0.2 \mu \mathrm{m}$. When pulling at microbeads bound to neutrophil microvilli, Shao et al. (1998) found that forces lower than $34 \mathrm{pN}$ triggered elongation with a proportion-

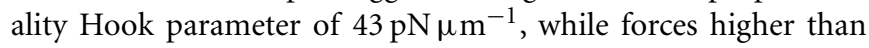
$61 \mathrm{pN}$ separated the plasma membrane from underlying cytoskeleton, thus generating tethers with an elongation rate proportional to the applied force. More recently, based on the brownian motion of microspheres bound to the tips of microvilli, Yao and Shao

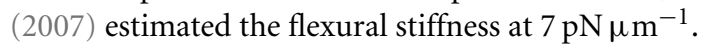

Thus, membrane unfolding is required for a spherical cell to spread on a surface. The maximum increase of apparent cell area after complete unfolding is 50-100\% (Evans and Yeung, 1989; Bruehl et al., 1996). Further area increase may require fusion of intracellular vesicles with plasma membranes, which may occur a few minutes after the onset of spreading (Gauthier et al., 2009).

We shall use this information to estimate the constraints experienced by a blood leukocyte made to stop in a specific area in blood vessels.

\section{EFFECT OF FLOW ON BLOOD LEUKOCYTES}

Blood flow is very different in millimeter diameter arteries and micrometer-diameter capillary vessels. Here, we shall focus on postcapillary venules with a diameter of several tens of micrometers, since they are a typical region of leukocyte arrest. As recalled on Figure 1A, the blood velocity near the vessel wall at any point $\mathrm{M}$ is parallel to the vessel axis and close to G.z, where $z$ is the distance between $\mathrm{M}$ and the wall, and $G$ (in second ${ }^{-1}$ ) is called the wall shear rate. Typical wall shear rates of a few hundreds of $\mathrm{s}^{-1}$ are found in postcapillary venules (Atherton and Born, 1973). The contact time between microvillus receptors and endothelium is thus lower than $1 \mathrm{~ms}$ (Zhao et al., 2001). This is the time allowed for initial tethering of cells to the endothelial surface. What happens then?

The force applied on a $8 \mu \mathrm{m}$ diameter leukocyte when the shear rate is $200 \mathrm{~s}^{-1}$ is $\sim 102 \mathrm{pN}$ (Figure 1B). The force on a Pselectin-PSGL-1 couple of $80 \mathrm{~nm}$ length may be sevenfold higher than the force on the cell (Figure 1C; Pierres et al., 1995). If the bond is located at the tip of a protrusion of $0.3 \mu \mathrm{m}$ length, the force will be 3.7 -fold higher than the force on the cell. This may induce tether formation if the receptor is not firmly anchored to the cell cytoskeleton. This was actually observed (Schmidtke and Diamond, 2000; Sundd et al., 2010, 2012). Thus a few bonds located at the tip of microvilli may not be sufficient to immobilize a leukocyte. Repeated bond formation and rupture will generate

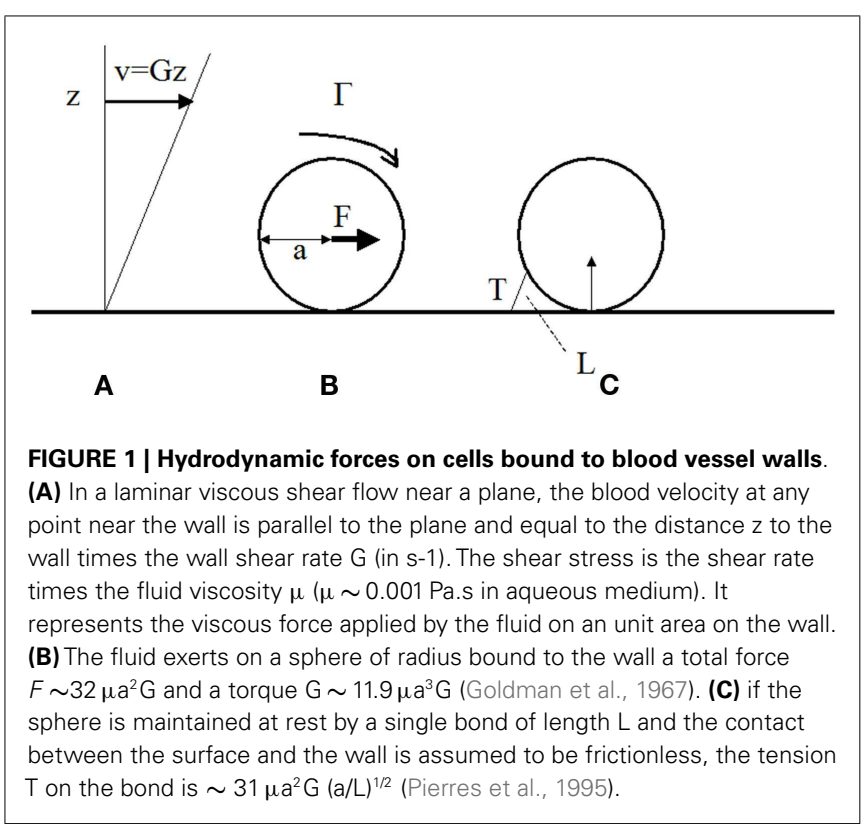


a rolling motion. Molecular contacts between leukocyte receptors and endothelial ligands may then last several tens of milliseconds rather than milliseconds for freely flowing cells. This may permit integrin-mediated attachments.

Thus, stopping a leukocyte on the blood vessels will need to resist local pulling forces between 100 and $700 \mathrm{pN}$. We need know how many adhesion receptors are needed to fulfill this task. Results accumulated during the last two decades may provide a clear answer to this question.

\section{NEW METHODS AND CONCEPTS PROVIDE US WITH QUANTITATIVE INFORMATION ON THE PROPERTIES OF BOND FORMATION AND DISSOCIATION BETWEEN SURFACE-ATTACHED MOLECULES Inability of the conventional framework to account for interactions between surface-attached molecules}

As previously reviewed (Bongrand, 1999; Zhu et al., 2002; Robert et al., 2007), the interaction between two molecules A and B in solution is well accounted for by two numbers, the association rate $k_{\text {on }}$ and dissociation rate $k_{\text {off }}$ :

$$
\mathrm{A}+\mathrm{B} \underset{k_{\text {off }}}{\stackrel{k_{\text {on }}}{\rightleftarrows}} \mathrm{AB}
$$

$d[\mathrm{AB}] / d t=k_{\text {on }}[\mathrm{A}][\mathrm{B}]-k_{\text {off }}[\mathrm{AB}]$, the ratio $k_{\mathrm{on}} / k_{\text {off }}$ is the affinity constant $K_{\mathrm{a}}$.

However, this conventional framework could not account for interactions between membrane-bound receptors and ligands: Firstly, bonds formed between surface-bound molecules are often subjected to external forces, and until recently no information was available on the effect of forces on bond lifetime. Secondly, as emphasized earlier, even the dimension of association rate between surface-bound molecules (corresponding to so-called 2D conditions) is different from the dimension of conventional (3D) association rates as defined in Eq. 1 (Pierres et al., 2001). Thirdly, 2D conditions impose special constraints on multivalent associations. We shall address these points sequentially.

\section{Rupture of bonds between surface-attached molecules}

During the last two decades, experiments based on laminar flow chambers (Kaplanski et al., 1993; Pierres et al., 1995), atomic force microscopes (Florin et al., 1994), the biomembrane force probe (Merkel et al., 1999), or optical tweezers (Nishizaka et al., 1995) allowed us to study single-bond formation and rupture between surface-attached molecules subjected to controlled forces. Bond rupture under force often followed a simple formula (Chen and Springer, 2001; Evans et al., 2010) previously suggested by Bell (1978):

$$
k_{\text {off }}(F)=k_{\text {off }}(0) \exp \left(F / F^{0}\right)
$$

where $k_{\text {off }}(F)$ is the rupture frequency (in $\mathrm{s}^{-1}$ ) of a single-bond subjected to a distractive force F. A simple interpretation of this formula can be obtained by viewing bond rupture as the passage of a molecular complex $\mathrm{AB}$ from a bound state at zero separation to a free state that is reached by crossing an energy barrier of height $W$ at separation distance $d$ (Figure 2). According to Boltzmann's law, the probability of barrier-crossing should be proportional to

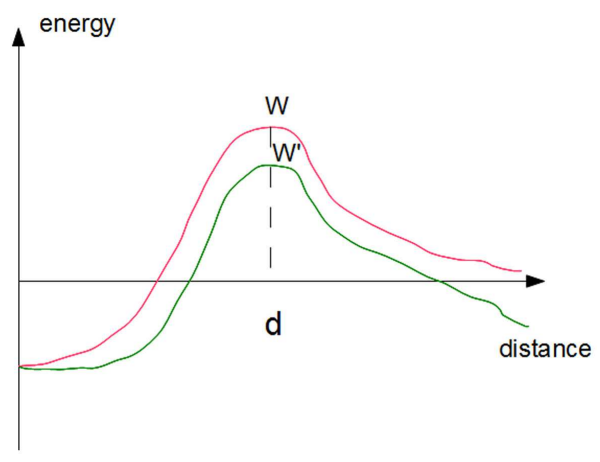

FIGURE 2 | Effect of forces on the kinetics of bond rupture. The simplest approximation consists of representing the free energy of a ligand-receptor complex as a simple function of the distance between ligand and receptor surfaces (red curve). Rupture requires the crossing of an energy barrier of height $W$. The rupture rate may be viewed as the product of the frequency of attempts at crossing times the success probability that is proportional to Boltzmann's factor $\exp \left(-W / k_{\mathrm{B}} T\right)$. Applying a force will decrease the barrier height by the product F.d, i.e., the force times the distance between the barrier and the equilibrium distance, thus multiplying the escape frequency by $\exp \left(F d / k_{\mathrm{B}} T\right)$.

$\exp \left(-W / k_{\mathrm{B}} \mathrm{T}\right)$, where $k_{\mathrm{B}}$ is Boltzmann's constant and $\mathrm{T}$ is the absolute temperature. Applying a force $F$ will decrease $W$ by the product $F d$ (Figure 2) thus multiplying the rupture frequency $k_{\text {off }}$ by $\exp \left(F d / k_{\mathrm{B}} \mathrm{T}\right)$. Bell estimated at $0.5 \mathrm{~nm}$ the order of magnitude of parameter $\mathrm{d}$ for an antigen-antibody interaction corresponding to the depth of an antibody binding site, leading to an estimate of $\sim 8 \mathrm{pN}$ for parameter $F^{\circ}=k_{\mathrm{B}} \mathrm{T} / d$. More detailed discussion may be found in a number of papers following Eyring's (1935) and Kramer's (1940) seminal papers (Hänggi et al., 1990; Evans and Ritchie, 1997; Dudko et al., 2008). The rupture frequency and force coefficient $\mathrm{F}^{\circ}$ for a number of receptors including selectins, integrins, cadherins, or antibodies were often on the order of $1-100 \mathrm{pN}$ and $0.01-10 \mathrm{~s}^{-1}$. Depending on molecule conformation, the forcefree rupture frequency of LFA-1/ICAM-1 bond varied between 0.008 and $2 \mathrm{~s}^{-1}$, with a force coefficient of $7-10 \mathrm{pN}$ (Evans et al., 2010). However, the above results are only an approximation and single molecule studies confirmed that bond rupture is a complex process requiring multiple barrier-crossing events (Pierres et al., 1995; Merkel et al., 1999; Derenyi et al., 2004).

The catch-bond phenomenon, which is highly relevant to leukocyte-endothelium interaction, was predicted on the basis of thermodynamical reasoning by noticing that a disruptive force might decrease bond rupture frequency $k_{\text {off }}$, although it had to decrease binding affinity $k_{\text {on }} / k_{\text {off }}$. Bonds displaying such a strange behavior were dubbed "catch bond," in contrast with "ordinary" bonds that were called "slip bonds," responding to disruptive forces with increased rupture frequency (Dembo et al., 1988). A few years later, it was reported that L-selectin-mediated rolling required a minimal shear level, suggesting that L-selectin might form catch bonds (Finger et al., 1996). More recently, it was demonstrated with flow chambers that a lectin-like bacterial adhesin formed catch bonds (Thomas et al., 2002), and a similar property was demonstrated on P-selectin/PSGL-1 interaction with both flow 
chamber and atomic force microscopy (Marshall et al., 2003): Bond lifetime displayed a fairly sharp maximum in presence of a pulling force close to $30 \mathrm{pN}$. P-selectin/PSGL-1 thus displayed catch-bond behavior in presence of a force ranging between 0 and $30 \mathrm{pN}$. Theoretical studies led to the conclusion that actual biomolecules interactions are much more complex that sketched on Figure 2. Thus, a catch-bond behavior might be accounted for by the existence of two dissociation pathways (Pereverzev et al., 2005).

\section{Formation of bonds between surface-attached molecules}

The rate of bond formation between two surfaces bearing known receptors and ligands cannot be derived from a "2-dimensional on-rate constant" since it is dependent on a number of parameters that are extrinsic to the receptor and ligand, including distance between surfaces, lateral mobility of receptors and ligands, length and flexibility of the links between binding sites and membranes, and behavior of surrounding molecules. First, it was suggested that the $3 \mathrm{D} k_{\text {on }}$ (a number expressed in $\mu \mathrm{m}^{2}$ molecule ${ }^{-1} \mathrm{~s}^{-1}$ ) had to be replaced with a function $k_{\text {on }}(d)$ representing the frequency (in $\mathrm{s}^{-1}$ ) of bond formation between a ligand and a receptor molecules maintained at distance $d$ (Pierres et al., 1996). The function $k_{\text {on }}(d)$ could in principle be derived experimentally by simultaneous determination of the binding frequency of receptor-bearing microspheres and ligand-coated surfaces and microsphere-tosurface distance (Pierres et al., 1998). However, other experiments show that this seemingly straightforward method may be difficult to use. Indeed, robust receptor-ligand association may not be immediate, and require a non-negligible amount of time for progressive crossing of barriers from less stable to more stable binding states (Pierres et al., 1995; Marshall et al., 2005; Pincet and Husson, 2005). This point was addressed experimentally in a model system (Robert et al., 2009): The formation of an ICAM-anti-ICAM-1 bond required a minimal contact time of about $10 \mathrm{~ms}$ to resist a disruptive force of order of $100 \mathrm{pN}$ during at least $200 \mathrm{~ms}$. This challenges the current framework used to describe bond formation (Eq. 1): the probability of bond formation between a ligand and a receptor is not proportional to the contact time. It is 0 if contact is shorter than some threshold, and 1 above this threshold. The threshold is dependent on the sensitivity of bond detection. More experiments are needed to check the relevance of these results to integrin-ligand associations. This is made more difficult to study experimentally by the dependence of integrin conformation on interactions with underlying membranes. However, since antigenantibody association is very rapid, it is likely that kinetic effects may be found on most biological systems.

\section{Difficulty of relating multivalent interactions to monovalent interactions when surface-bound molecules are considered}

Theoretical studies (Seifert, 2000) have long revealed the difficulty of relating the properties of multivalent attachments to single bonds. This difficulty is a consequence of two important processes: force-sharing and rebinding. This point can be made easier to grasp by comparing the lifetime of attachments mediated by one or two identical bonds.

First, let us consider the effect of an external force F: if the force is equally shared between both bonds, the lifetime of each bond will be divided by $\exp \left(F / 2 F^{\circ}\right)$, where $F^{\circ}$ is the aforementioned force constant. After the rupture of a first bond, the whole force will be applied on the remaining one, thus inducing rapid failure. The dissociation rate of the divalent attachment will thus vary as $\exp \left(F / 2 F^{\circ}\right)$. In absence of force-sharing, the force is expected to divide attachment lifetime by $\exp \left(F / F^{\circ}\right)$. As a numerical example, a disrupting force of $40 \mathrm{pN}$ is expected to reduce the lifetime of a single-bond attachment mediated by an integrin of force constant $\mathrm{F}^{\circ} \sim 7 \mathrm{pN}$ by 300 , while the lifetime of a force-sharing divalent attachment will be reduced by only 17 .

The importance of rebinding may be still more impressive. Let us consider an attachment involving high affinity receptors such that bond formation is much more frequent than bond rupture. If a bond has a high probability to reform after spontaneous rupture, provided a second bond maintains surfaces in close contact, the lifetime of a divalent attachment may be nearly infinite, and in any case much higher than that of a monovalent attachment.

Recently, this point was addressed experimentally by comparing the lifetime of monovalent and divalent attachments formed between ICAM-1-coated surfaces and anti-ICAM-1coated microspheres (LoSchiavo et al., 2012): the proportion of divalent attachments resisting a force of $30 \mathrm{pN}$ for at least $5 \mathrm{~s}$ was 3.7-fold higher than that of monovalent attachments. This was due to a combination of force-sharing, bond maturation and rebinding. Importantly, rebinding requires a tight proximity between receptors.

Remarkably, clustering has been recognized by many authors as a key feature of integrin function (Cambi et al., 2006; SelhuberUnkel et al., 2008; van Zanten et al., 2009), although other experiments were compatible with the assumption that conformational activation of individual molecules might suffice to initiate adhesion in absence of any significant modulation of clustering (Kim et al., 2004).

The physical background we summarized will help us understand the mechanisms of integrin-mediated leukocyte arrest.

CELL ACTIONS REQUIRED FOR INTEGRIN-MEDIATED ARREST Selectins seem unable to induce durable cell arrests (Lawrence and Springer, 1991) and integrins are required for this purpose. Key events following chemokine-mediated activation (Montresor et al., 2012) are depicted on Figures 3A,B as described below.

\section{INTEGRIN FUNCTIONAL ACTIVATION}

Chemokines were shown to induce within seconds an extension of previously bent integrins and opening of binding sites resulting in an affinity increase (Montresor et al., 2012) as a consequence of both increase of binding rate (Vitte et al., 2004; Zhang et al., 2005) and bond lifetime. The binding of immobilized ligands may result in further activation (Alon and Dustin, 2007).

\section{MEMBRANE ALIGNMENT}

Membrane deformation is required to allow contact between integrin molecules and ICAM-1 ligand. Indeed, the length of the ICAM-1 + LFA- 1 couple is about $40 \mathrm{~nm}$, less than the size of the longest microvilli, and LFA-1 is not concentrated on the tip of microvilli in a resting cell (Erlandsen et al., 1993). Molecular contact may thus require at least one of three processes: (i) forces applied on the tip of microvilli may cause significant enlargement and shortening (Sundd et al., 2010). (ii) Chemokines may 


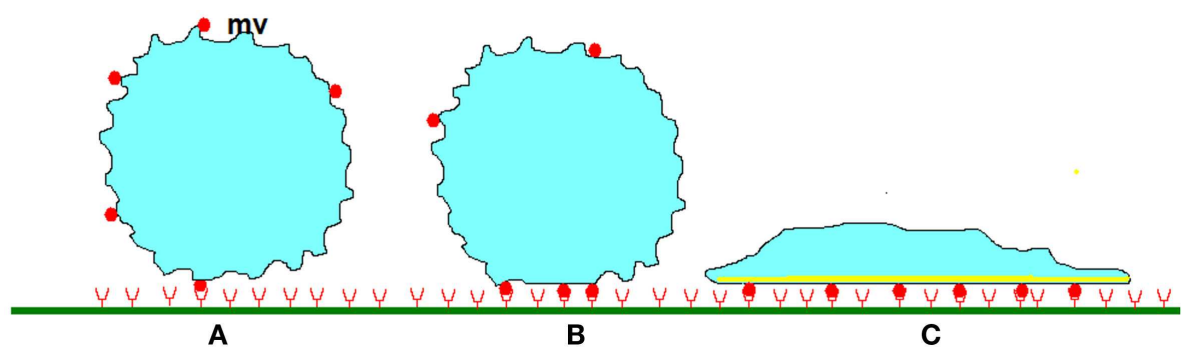

FIGURE 3 | Stabilization of leukocyte attachment to the blood vessels. (A) When a cell studded with protrusions (mv) of several hundreds of $\mathrm{nm}$ length encounters a plane surface, contact between membrane receptors such as selectins or integrins (red disks) and their ligands (red half circles) of total length lower than $50-100 \mathrm{~nm}$ can only occur on the tip of protrusions, allowing formation of a low number of bonds. As indicated in text, very high association rates are needed to tether freely flowing leukocytes within a molecular contact shorter than a few milliseconds and initiate rolling. (B) Within the following tens of seconds, rolling cells undergo (i) micrometer-scale flattening similarly to liquid droplets encountering a wettable surface, (ii) submicrometer-scale smoothing of microvilli, first due to compressive forces, and possibly later to intracellular signaling triggered by chemokines. (iii) lateral diffusion of membrane receptors that are trapped into the contact area. At some moment, these phenomena induce cell arrest. (C) Further attachment strengthening may involve a more extensive increase of contact area as a consequence of spreading, increase of membrane stiffness due to local cytoskeleton reinforcement, and possibly increase of the strength of membrane receptors attachment to underlying cytoskeleton, thus preventing further lateral displacement. trigger within seconds ezrin-radixin-moesin dephosphorylation resulting within tens of seconds in microvillus disruption and membrane release (Brown et al., 2003). (iii) Membrane release may enhance transverse membrane undulations as reported at interfaces between glass coverslips and immune cells microscopy (Zidovska and Sackmann, 2006; Pierres et al., 2008; Crétel et al., 2011). Early reports done with electron microscopy (Foa et al., 1988) or fluorescence microscopy (Dustin, 1997) demonstrated submicrometer membrane alignment within minutes (Foa et al., 1988) or even tens of seconds (Dustin, 1997) following cell-surface contact. More recent studies done with interference reflection microscopy showed that the initial attachment of monocytic cells to adhesive surfaces was followed within a minute by progressive interaction tightening that might be interpreted as a nanometer scale alignment of interacting surfaces (Pierres et al., 2002, 2008).

\section{LATERAL REDISTRIBUTION OF INTEGRINS}

\section{Integrin alignment with ligands on opposing surfaces}

Integrins likely need lateral mobility to align along ligands on opposing surfaces, and the mobility requirement may be higher as lower ligand density (Chan et al., 1991). A positive correlation between lymphocyte adhesiveness to ICAM-1-coated surfaces and LFA-1 membrane mobility was reported (Kucik et al., 1996). More recently, Bakker et al. (2012) concluded that monocytes required a mobile population of surface integrins to adhere to ICAM-1-coated surfaces under static or flow conditions.

The difficulty of relating integrin-cytoskeletal association to cell adhesiveness (Lub et al., 1997) may be due to (i) heterogeneity of mobilities of LFA-1 molecules on a given cell, (ii) contradictory need for mobility (to allow ligand-receptor contact) and integrin-cytoskeleton attachment (to ensure mechanical strength), (iii) dependence of integrin-cytoskeleton interaction on cell differentiation and activation status (Cairo et al., 2006).

\section{Integrin clustering}

Since the lifetime of a newly formed LFA-1/ICAM-1 bond may be quite short if full activation has not been triggered, a pre-clustering of LFA-1 molecules might strongly enhance the duration of initial attachment and allow for the formation of additional bonds. This may be less necessary if integrins are in a fully activated state. Note that the precise chronology of clustering remains controversial. Studies made on phagocytes strongly suggest that integrin clustering preceded ligand binding (Detmers et al., 1987; Cambi et al., 2006; van Zanten et al., 2009). Other authors concluded that the binding of multivalent ligands was required to induce a clustering of lymphocyte integrins (Kim et al., 2004).

In conclusion, integrin-mediated cell arrest likely results from a combination of conformational changes (within seconds), nanotopographical membrane rearrangement to allow contact with ligand-bearing surfaces (within tens of seconds), and lateral diffusion of integrin molecules to align along ligands, form clusters, or both. However, other experiments suggest that initial arrest is followed within minutes by an attachment strengthening phase including several actions, as described below.

\section{MEMBRANE STRENGTHENING AND ACTIVE SPREADING}

Arrest stabilization may include at least three concomitant processes (Figure 3C) That we shall describe separately.

\section{Reinforcement of cell stiffness in contact area}

Monitoring cell-surface detachment under flow revealed significant cell deformation during detachment (Mège et al., 1986; Cao et al., 1998). Flow induced detachment is a peeling process, with a sequential detachment of membrane stripes involving a few bonds. The rupture force therefore increases in parallel with membrane stiffness (Evans, 1985). This reasoning is supported by experimental evidence (Rees et al., 1977; Badley et al., 1981). This supports the functional importance of microfilament concentration in cell-surface contact areas (André et al., 1991).

\section{Reinforcement of integrin anchoring to underlying cytoskeleton}

Strong integrin-mediated cell attachment requires that integrins be strongly attached to the cell-surface. Microfilaments indeed 
enhanced integrin-mediated attachment in some experiments (Lub et al., 1997). Thus, integrin-cytoskeleton interaction may be a multiphasic, time-dependent process: initial integrin release should favor alignment with ligand and clustering, binding of ligand-attached integrins to cytoskeletal elements would then strengthen overall attachment. This is consistent with the multiplicity of integrin states (free versus immobile, isolated versus clustered) on the cell membrane (Cairo et al., 2006).

\section{Increase of cell-surface interaction area through active spreading}

Spreading may follow and markedly stabilize cell adhesion when this is mediated by suitable receptors (Pierres et al., 2002). A frequent consequence of integrin-ligand association is the generation of signaling cascades (this is outside-in signaling) inducing rapid spreading (Abram and Lowell, 2009). This was demonstrated not only with LFA-1 (Feng et al., 2012) but also $\beta 1$ (Zeller et al., 2010) or $\beta 3$ (Kasirer-Friede et al., 2007) integrins.

In conclusion, LFA-1-mediated leukocyte arrest on endothelial cells is a key step of inflammation. This strongly depends on a combination of integrin-mediated processes that are likely to involve a network of tens of proteins and hundreds of interactions (Ley et al., 2007; Zaidel-Bar et al., 2007). A possible way of understanding the functions of these networks is to analyze the perturbation (Ku et al., 2012) generated by the deficiency of a specific component. A recently characterized defect of FERMT3 gene resulting in abnormal or absent kindlin-3 protein provides a good example.

\section{LEUKOCYTE ADHESION DEFICIENCY TYPE III EXEMPLIFIES THE CONSEOUENCES OF A SPECIFIC INTEGRIN DEFICIENCY}

Leukocyte adhesion deficiency (LAD) type I was identified three decades ago as a syndrome caused by a partial or complete defect of integrin $\beta 2$ chain expression. Symptoms included sensitivity to bacterial infection, leukocytosis, and absence of pus formation. In 1997 , a functional $\beta 2$-integrin deficiency associated with a bleeding tendency and abnormal platelet spreading was reported in a patient suffering symptoms resembling but somewhat milder than LAD-I (Kuijpers et al., 1997). This was called LAD-I/variant or LAD-III (Alon and Etzioni, 2003). It was ascribed to a defective expression of kindlin-3 (Kuijpers et al., 2009). Kindlin-3 is expressed on hematopoietic cells and binds the C-terminal $\mathrm{NXXY} / \mathrm{F}$ site of integrin $\beta 2$ chain, thus stabilizing active conformations together with talin (Abram and Lowell, 2009). Kindlin-3 overexpression induced integrin clustering (Feng et al., 2012). Also, Kindlin-3 participates integrin-mediated cell spreading, which is considered as a consequence of outside-in signaling (Abram and Lowell, 2009; Meves et al., 2009).

Analyzing the function of kindlin-3-defective cells might give valuable information on both the role of kindlin-3 in integrin function and the interrelation of the physical events described in this review. We used the availability of a LAD-III patient to investigate neutrophils and T lymphocytes: we quantified three steps of the arrest sequence triggered by several integrin activators (Robert et al., 2011): (i) cell adhesion to ICAM-1-coated surfaces was monitored in a low shear flow $\left(20 s^{-1}\right)$. Under these conditions a single molecular bond could induce a detectable arrest (Pierres et al., 2008a), and the total arrest frequency should thus reflect the presence of extended integrins. (ii) The frequency of durable arrests ( 2 min or more) should account for a combination of integrin clustering and high affinity state acquisition. (iii) Finally, the molecular contact area between leukocytes and ICAM1-coated surfaces after $15 \mathrm{~min}$ interaction, was used as a reporter of membrane-surface alignment and spreading. Cells were stimulated with $\mathrm{Mn}^{++}$, which stabilizes active conformations without involving intracellular cascades, or chemotactic peptide fMLF, phorbol myristate acetate (PMA), and calcium ionophore ionomycin that are know to activate cells by triggering signaling cascades. The following conclusions were obtained:

(i) A clear hierarchy of measured parameters was obtained: spreading could not be normal if durable arrest frequency was normal, and durable arrest could no be stimulated in patients' cells if total arrests were lacking.

(ii) As expected, $\mathrm{Mn}^{++}$-induced arrests were normal in patients cells, validating the possibility of detecting individual interactions provided integrin unbending was correctly induced.

(iii) Total arrest frequency was normal, but durable arrest frequency was decreased in PMLF-stimulated neutrophils, confirming the importance of active cell functions to stabilize arrests in contrast with short-term molecular interactions (Pierres et al., 1994). This is consistent with the hypothesis that the integrin extension induced by fMLF (Diamond and Springer, 1993; El Azreq et al., 2011) might be obtained in absence of kindlin-3. It was not feasible to ascribe the arrest stabilization and spreading defects to incomplete integrin activation or defect of fMLF-induced clustering (Detmers et al., 1987). Interestingly, Lefort et al. (2012) used a murine model to compare the consequences of talin and kindlin-3 deficiencies: they concluded that talin was sufficient to trigger integrin extension and enable slow rolling, but synergy with kindlin-3 was required to induce high affinity conformation and cell arrest under flow.

(iv) Phorbol myristate acetate (PMA) was reported to induce both mobility changes (Kucik et al., 1996) and at least partial affinity increase (Lollo et al., 1993) in stimulated leukocytes. PMA treatment triggered normal arrest frequency and duration in patients's neutrophils while $\mathrm{T}$ lymphocytes were markedly defective for both parameters. This is in line with a previous finding that a same pharmacological treatment had opposing effects on lymphocyte and neutrophil integrins (Marwali et al., 2003; Solomkin et al., 2007; Abram and Lowell, 2009).

(v) Surprisingly, T lymphocytes from LAD-III patients displayed abnormal spreading on anti-CD3-coated surfaces. Interestingly, LFA-1 was recently found to be involved in T lymphocyte activation by anti-CD3-coated surfaces, even in absence of ICAM-1 (Li et al., 2009) and kindlin-3 was found to lower the threshold for NK cell activation (Gruda et al., 2012). This suggests additional roles for kindlin-3. In contrast to our results, Feigelson et al. (2011) found normal ICAM-1-independent spreading of $\mathrm{T}$ lymphocytes from another LAD-III patient. That different kindlin-3defective cell populations might display different deficiencies is in line with a report showing that only one of two 
LAD-III siblings suffered osteopetrosis (Jurk et al., 2010). Gene-gene interactions may provide a likely explanation for phenotypic differences between two subjects or cell population sharing a common genetic deficiency (Cordell, 2009).

\section{CONCLUSION}

The recent expansion of molecular biology techniques allowing high throughput analysis of gene sequence and expression in individuals makes it a prominent goal to define with maximum accuracy the function of newly characterized genes and proteins. This is a formidable task due to the complexity of molecular networks driving cell functions. The current challenge is to

\section{REFERENCES}

Abram, C. L., and Lowell, C. A. (2009). The ins and outs of leukocyte integrin signaling. Annu. Rev. Immunol. 27, 339-362.

Alon, R., Chen, S., Puri, K. D., Finger, E. B., and Springer, T. A. (1997). The kinetics of L-selectin tethers and the mechanics of selectinmediated rolling. J. Cell Biol. 138, 1169-1180.

Alon, R., and Dustin, M. L. (2007). Force as facilitator of integrin conformational changes during leukocyte arrest on blood vessels and antigen-presenting cells. Immunity 26, 17-27.

Alon, R., and Etzioni, A. (2003). LADIII, a novel group of leukocyte integrin activation deficiencies. Trends Immunol. 24, 561-566.

Alon, R., Kassner, P. D., Woldemar Carr, M., Finger, E. B., Hemler, M. E., and Springer, T. A. (1995). The integrin VLA-4 supports tethering and rolling in flow on VCAM-1. J. Cell Biol. 128, 1243-1253.

André, P., Gabert, J., Benoliel, A.M., Capo, C., Boyer, C., SchmittVerhulst, A. M., et al. (1991). Wild type and tailless CD8 display similar interaction with microfilaments during capping. J. Cell. Sci. 100, 329-337.

Atherton, A., and Born, G. V. R. (1972). Quantitative investigations on the adhesiveness of circulating polymorphonuclear leukocytes to blood vessel walls. J. Physiol. (Lond.) 222, 447-474.

Atherton, A., and Born, G. V. R. (1973). Relationship between the velocity of rolling granulocytes and that of the blood flow in venules. J. Physiol. (Lond.) 233, 157-165.

Badley, R. A., Woods, A., and Rees, D. A. (1981). Cooperativity of concanavalin A patching and its influence on cytoskeleton changes in fibroblast rounding and detachment. J. Cell. Sci. 47, 349-363.
Bakker, G. J., Eich, C., Torreno-Pina, J. A., Diez-Ahedo, R., Perez-Samper, G., van Zanten, T. S., et al. (2012). Lateral mobility of individual integrin nanoclusters orchestrates the onset for leukocyte adhesion. Proc. Natl. Acad. Sci. U.S.A. 109, 4869-4874.

Bell, G. I. (1978). Models for the specific adhesion of cells to cells. Science 200, 618-627.

Bongrand, P. (1999). Ligand-receptor interactions. Rep. Progr. Phys. 62, 921-968.

Brown, M. J., Nijhara, R., Hallam, J. A., Gignac, M., Yamada, K. M., Erlandsen, S. L., et al. (2003). Chemokine stimulation of human peripheral blood $\mathrm{T}$ lymphocytes induces rapid dephosphorylation of ERM proteins, which facilitates loss of microvilli and polarization. Blood 102, 3890-3899.

Bruehl, R. E., Springer, T. A., and Bainton, D. F. (1996). Quantitation of L-selectin distribution on human leukocyte microvilli by immunogold labeling and electron microscopy. $J$. Histochem. Cytochem. 44, 835-844.

Brunk, D. K., Goetz, D. J., and Hammer, D. A. (1996). Sialyl Lewis $\mathrm{X} /$ E-selectin-mediated rolling in a cell-free system. Biophys. J. 71, 2902-2907.

Cairo, C. W., Mirchev, R., and Golan, D. E. (2006). Cytoskeletal regulation couples LFA-1 conformational changes to receptor lateral mobility and clustering. Immunity 25, 297-308.

Cambi, A., Joosten, B., Koopman, M., de Lange, F., Beeren, I., Torensma, R., et al. (2006). Organization of the integrin LFA-1 in nanoclusters regulates its activity. Mol. Biol. Cell 17, 4270-4281.

Campbell, J. J., Hedrick, J., Zlotnik, A., Siani, M. A., Thompson, D. A., and Butcher, E. C. (1998). Chemokines and the arrest of lymphocytes rolling under flow conditions. Science 279, 381-384.

find tractable ways of analyzing these networks. A possible way of approaching this goal may consist of determining the functional consequences of a well defined network perturbation (Ku et al., 2012). As shown in this review, recent studies provided a quantitative description of the elementary physical processes contributing cell functions (e.g., molecule clustering, molecular interactions, conformational change all contribute integrin-mediated adhesion). This should allow us to draw networks connecting these elementary physical events. These "function networks" should be simpler than the huge networks involving hundreds of molecular components and interactions that are presently available (ZaidelBar et al., 2007). The analysis of well defined genetic defects found in patients may be very informative in this domain.

Cao, J., Donell, B., Deaver, D. R., Lawrence, M. B., and Dong, C. (1998). In vitro side-view imaging technique and analysis of human T-leukemic cell adhesion to ICAM1 in shear flow. Microvasc. Res. 55, 124-127.

Chan, P. Y., Lawrence, M. B., Dustin, M. L., Golan, D. E., and Springer, T. A. (1991). Influence of receptor lateral mobility on adhesion strengthening between membranes containing LFA-3 and CD2. J. Cell. Biol. 115, 245-255.

Chen, S., and Springer, T. A. (2001). Selectin receptor-ligand bonds: formation limited by shear rate and dissociation governed by the Bell model. Proc. Natl. Acad. Sci. U.S.A. 98, 950-955.

Chigaev, A., and Sklar, L. A. (2012). Aspects of VLA-4 and LFA-1 regulation that may contribute to rolling and firm adhesion. Front. Immunol. 3:242. doi:10.3389/fimmu.2012.00242

Cordell, H. J. (2009). Detecting genegene interactions that underlie hman diseases. Nat. Rev. Genet. 10, 392-404.

Crétel, E., Touchard, D., Bongrand, P., and Pierres, A. (2011). A new method for rapid detection of $\mathrm{T}$ lymphocyte decision to proliferate after encountering activating surfaces. J. Immunol. Methods 364, 33-39.

Dembo, M., Torney, D. C., Saxman, K., and Hammer, D. (1988). The reaction-limited kinetics of membrane-to-surface adhesion and detachment. Proc. R. Soc. Lond. B Biol. Sci. 234, 55-83.

Derenyi, I., Bartolo, D., and Ajdari, A. (2004). Effects of intermediate bound states in dynamic force spectroscopy. Biophys. J. 86, 1263-1269.

Detmers, P. A., Wright, S. D., Olsen, E., Kimball, B., and Cohn, Z. A. (1987). Aggregation of complement receptors of human neutrophils in the absence of ligand. J. Cell Biol. 105, 1137-1145.

Diamond, M. S., and Springer, T. A. (1993). A subpopulation of Mac1 (CD11b/CD18) molecules mediates neutrophil adhesion to ICAM1 and fibrinogen. J. Cell Biol. 120, 545-556.

Dudko, O. K., Hummer, G., and Szabo, A. (2008). Theory, analysis, and interpretation of singlemolecule force spectroscopy experiments. Proc. Natl. Acad. Sci. U.S.A. 105, 15755-15760.

Dustin, M. L. (1997). Adhesive bond dynamics in contacts between $\mathrm{T}$ lymphocytes and glass-supported planar bilayers reconstituted with the immunoglobulin-related adhesion molecule CD58. J. Biol. Chem. 272, 15782-15788.

El Azreq, M.-A., Garceau, V., and Bourgoin, S. G. (2011). Cytohesin-1 regulates $\mathrm{MLF}$-mediated activation and functions of the $\beta 2$ integrin Mac- 1 in human neutrophils. J. Leukoc. Biol. 89, 823-836.

Erlandsen, S. L., Hasslen, S. R., and Nelson, R. D. (1993). Detection and spatial distribution of the $\alpha 2$-integrin (Mac-1) and L-selectin (LECAM-1) adherence receptors on human neutrophils by high-resolution field emission SEM. J. Histochem. Cytochem. 41, 327-333.

Evans, E., Kinoshita, K., Simon, S., and Leung, A. (2010). Long-lived, highstrength states of ICAM-1 bonds to $\beta 2$ integrin. I: lifetimes of bonds to recombinant $\alpha \mathrm{L} \beta 2$ under force. Biophys. J. 98, 1458-1466.

Evans, E., Leung, A., Hammer, D., and Simon, S. (2001). Chemically distinct transition states govern rapid dissociation of single L-selectin bonds under force. Proc. Natl. Acad. Sci. U.S.A. 98, 3784-3789.

Evans, E., and Ritchie, K. (1997). Dynamic strength of molecular adhesion bonds. Biophys. J. 72, 1541-1555. 
Evans, E., and Yeung, A. (1989). Apparent viscosity and cortical tension of blood granulocytes determined by micropipet aspiration. Biophys. J. 56, 151-160.

Evans, E. A. (1985). Detailed mechanics of membrane-membrane adhesion and separation. I. Continuum of molecular cross-bridges. Biophys. J. 48, 175-183.

Evans, E. V., Leung, A., Heinrich, V., and Zhu, C. (2004). Mechanical switching and coupling between two dissociation pathways in a P-selectin adhesion bond. Proc. Natl. Acad. Sci. U.S.A. 101, 11281-11286.

Eyring, H. (1935). The activated complex in chemical reactions. J. Chem. Phys. 3, 107-115.

Feigelson, S. W., Grabovsky, V., Manevich-Mendelson, E., Pasvolsky, R., Shulman, Z., Shinder, V., et al. (2011). Kindlin-3 is required for the stabilization of TCR-stimulated LFA-1:ICAM-1 bonds critical for lymphocyte arrest and spreading on dendritic cells. Blood 117, 7042-7052.

Feng, C., Li, Y.-F., Yau, Y.-H., Lee, H.-S., Tang, X.-Y., Xue, Z.-H., et al. (2012). kindlin-3 mediates integrin $\alpha \mathrm{L} \beta 2$ outside-in signaling, and it interacts with scaffold protein receptor for activated-C kinase 1 (RACK1). J. Biol. Chem. 287, 10714-10726.

Finger, E. B., Puri, K. D., Alon, R., Lawrence, M. B., von Andrian, U. H., and Springer, T. A. (1996). Adhesion through L-selectin requires a threshold hydrodynamic shear. Nature 379, 266-269.

Florin, E.-L., Moy, V. T., and Gaub, H. E. (1994). Adhesion forces between individual ligand-receptor pairs. Science 264, 415-417.

Foa, C., Mège, J. L., Capo, C., Benoliel, A.-M., Galindo, J. R., and Bongrand, P. (1988). T-cell-mediated cytolysis: analysis of killer and target cell deformability and deformation during conjugate formation. J. Cell. Sci. 89, 561-573.

Gauthier, N. C., Rossier, O. M., Mathur, A., Hone, J. C., and Sheetz, M. P. (2009). Plasma membrane area increases with spread area by exocytosis of a GPI-anchored protein compartment. Mol. Biol. Cell 20, 3261-3272.

Goldman, A. J., Cox, R. G., and Brenner, H. (1967). Slow viscous motion of a sphere parallel to a plane wall. II - Couette flow. Chem. Eng. Sci. 22, 653-660.

Grabovksy, V., Feigelson, S., Chen, C., Bleijs, D. A., Peled, A., Cinamon, G., et al. (2000). Subsecond induction of $\alpha 4$ integrin clustering by immobilized chemokines stimulates leukocyte tethering and rolling on endothelial vascular cell adhesion molecule 1 under flow conditions. J. Exp. Med. 192, 495-505.

Gruda, R., Brown, A. C. N., Grabovksy, V., Mizrahi, S., Gur, C., Feigelson, S. W., et al. (2012). Loss of kindlin-3 alters the threshold for NK cell activation in human leukocyte adhesion deficiency-III. Blood 120, 3915-3924.

Hänggi, P., Talkner, P., and Borkovec, M. (1990). Reaction-rate theory: fifty years after Kramers. Rev. Mod. Phys. 62, 251-342.

Herant, M., Marganski, W. A., and Dembo, M. (2003). The mechanics of neutrophils: synthetic modeling of three experiments. Biophys. J. 84, 3389-3413.

Hidalgo, A., Peired, A. J., Wild, M. K., Vestweber, D., and Frenette, P. S. (2007). Complete identification of E-selectin ligands on neutrophils reveals distinct functions of PSGL1, ESL-1, and CD44. Immunity 26, 477-489.

Horoyan, M., Benoliel, A.-M., Capo, C., and Bongrand, P. (1990). Localization of calcium and microfilament changes in mechanically stressed cells. Cell Biophys. 17, 243-256.

Jung, U., Norman, K. E., ScharffetterKochanek, K., Beaudet, A. L., and Ley, K. (1998). Transit time of leukocytes rolling through venules controls cytokine-induced inflammatory cell recruitment in vivo. J. Clin. Invest. 102, 1526-1533.

Jurk, K., Schultz, A. S., Kehrel, B. E., Räpple, D., Schulze, H., Möbest, D., et al. (2010). Novel integrin-dependent platelet malfunction in siblings with leukocyte adhesion deficiency-III (LAD-III) caused by a point mutation in FERMT3. Thromb. Haemost. 103, 1053-1064.

Kaplanski, G., Farnarier, C., Tissot, O., Pierres, A., Benoliel, A.-M., Alessi, M.-C., et al. (1993). Granulocyteendothelium initial adhesion. Analysis of transient binding events mediated by E-selectin in a laminar shear flow. Biophys. J. 64, 1922-1933.

Kasirer-Friede, A., Kahn, M. L., and Shattil, S. J. (2007). Platelet integrins and immunoreceptors. Immunol. Rev. 218, 247-264.

Kim, M., Carman, C. V., Yang, W., Salas, A., and Springer, T. A. (2004). The primacy of affinity over clustering in regulation of adhesiveness of the integrin $\alpha \mathrm{L} \beta 2$. J. Cell Biol. 20, 1241-1253.

Kramers, H. A. (1940). Brownian motion in a field of force and diffusion model of chemical reactions. Physica 7, 284-304.

$\mathrm{Ku}$, C.-J., Wang, Y., Weiner, O. D. Altschuler, S. J., and Wu, L. F. (2012). Network crosstalk dynamically changes during neutrophil polarization. Cell 149, 1073-1083.

Kucik, D. F., Dustin, M. L., Miller, J. M. and Brown, E. J. (1996). Adhesionactivating phorbol ester increases the mobility of leukocyte integrin LFA1 in cultured lymphocytes. J. Clin. Invest. 97, 2139-2144.

Kuijpers, T. W., van de Vijver, E., Weterman, M. A. J., de Boer, M., Tool, A. T. J., and van den Berg, T. K. (2009). LAD-1/variant syndrome is caused by mutations in FERMT3. Blood 113 , 4740-4746.

Kuijpers, T. W., van Lier, R. A. W., Hamann, D., deBoer, M., Thung, L. Y., Weening, R. S., et al. (1997). Leukocyte adhesion deficiency type 1 (LAD-1)/Variant A novel immunodeficiency syndrome characterized by dysfunctional beta2 integrins. J. Clin. Invest. 100, 1725-1733.

Kuwano, Y., Spelten, O., Zhang, H., Ley, K., and Zarbock, H. (2010). Rolling on E- or P-selectin induces the extended but not high-affinity conformation of LFA-1 in neutrophils. Blood 116, 617-662.

Lawrence, M. B., and Springer, T. A. (1991). Leukocytes roll on a selectin at physiologic flow rates:distinction from and prerequisite for adhesion through integrins. Cell 65, 859-873.

Lawrence, M. B., and Springer, T. A. (1993). Neutrophils roll on $\mathrm{E}$ selectin. J. Immunol. 151, 6338-6346.

Lawrence, M. B., and Springer, T. A (1994). Neutrophil tethering to and rolling on E-selectin are separable by requirement for L-selectin. Immunity 1, 137-145.

Lefort, C. T., and Ley, K. (2012). Neutrophil arrest by LFA-1 activation. Front. Immunol. 3:157. doi:10.3389/fimmu.2012.00157

Lefort, C. T., Rossaint, J., Moser, M. Petrich, B. G., Zarbock, A., Monkley, S. J., et al. (2012). Distinct roles for talin-A and kindlin-3 in LFA1 extension and affinity regulation. Blood 119, 4275-4282.

Ley, K., Laudanna, C., Cybulsky, M. I., and Nourshargh, S. (2007). Getting to the site of inflammation: the leukocyte adhesion cascade updated. Nat. Rev. Immunol. 7, 678-689.

Li, D., Molldrem, J. J., and Ma, Q. (2009). LFA-1 regulates CD8+ T cell activation via $\mathrm{T}$ cell receptor-mediated and LFA-1-mediated Erk 1/2 signal pathways. J. Biol. Chem. 284, 21001-21010.

LoSchiavo, V., Robert, P., Limozin, L., and Bongrand, P. (2012). Quantitative modeling assesses the contribution of bond strengthening, rebinding and force sharing to the avidity of biomolecule interactions. PLoS ONE 7:e44070. doi:10.1371/journal.pone.0044070

Lollo, B. A., Chan, K. W. H., Hanson, E. M., Moy, V. T., and Brian, A. A. (1993). Direct evidence for two affinity states for lymphocyte function-associated antigen 1 on activated T cells. J. Biol. Chem. 268, 21693-21700.

Lub, M., vanKooyk, Y., Vliet, S. J., and Figdor, C. G. (1997). Dual role of the actin cytoskeleton in regulating cell adhesion mediated by the integrin lymphocyte function associated molecule 1. Mol. Biol. Cell 8 , 341-351.

Marshall, B. T., Long, M., Piper, J. W., Yago, T., McEver, R. P., and Zhu, C. (2003). Direct observation of catch bonds involving cell-adhesion molecules. Nature 423, 190-193.

Marshall, B. T., Sarangapani, K. K., Lou, J., McEver, R. P., and Zhu, C. (2005). Force history dependence of receptor-ligand dissociation. Biophys. J. 88, 1458-1466.

Marwali, M. R., Rey-Ladino, J., Drolini, L., Shaw, D., and Takei, F. (2003). Membrane cholesterol regulates LFA-1 function and lipid raft heterogeneity. Blood 102, 215-222.

Mège, J. L., Capo, C., Benoliel, A.M., and Bongrand, P. (1986). Determination of binding strength and kinetics of binding initiation. A model study made on the adhesive properties of P388D1 macrophagelike cells. Cell Biophys. 8, 141-160.

Merkel, R., Nassoy, P., Leung, A., Ritchie, K., and Evans, E. (1999). Energy landscapes of receptorligand bonds explored with dynamic force spectroscopy. Nature 397, 50-53.

Meves, A., Stremmel, C., Gottschalk, K., and Fässler, R. (2009). The kindlin protein family: new members to the club of focal adhesion proteins. Trends Cell Biol. 19, 504-513.

Montresor, A., Toffali, L., Constantin, G., and Laudanna, C. (2012). Chemokines and the signaling modules regulating integrin affinity. Front. Immunol. 3:127. doi:10.3389/fimmu.2012.00127

Nishizaka, T., Miyata, H., Yoshikawa, H., Ishiwata, S., and Kinosita, K. Jr. (1995). Unbinding force of a single motor molecule of muscle measured 
using optical tweezers. Nature 377, 251-254.

Pereverzev, Y. V., Prezhdo, O. V., Thomas, W. E., and Sokurenko, E. V. (2005). Distinctive features of the biological catch bond in the jumpramp force regime predicted by the two-pathway model. Phys. Rev. E Stat. Nonlin. Soft Matter Phys. 72, 010903.

Pierres, A., Benoliel, A.-M., and Bongrand, P. (1995). Measuring the lifetime of bonds made between surface-linked molecules. J. Biol. Chem. 270, 26586-26592.

Pierres, A., Benoliel, A.-M., and Bongrand, P. (1996). Measuring bonds between surface-associated molecules. J. Immunol. Methods 196, 105-120.

Pierres, A., Benoliel, A.-M., and Bongrand, P. (2002). Cell fitting to adhesive surfaces: a prerequisite to firm attachment and subsequent events. Eur. Cell Mater. 3, 31-45.

Pierres, A., Benoliel, A.-M., and Bongrand, P. (2008a). Studying molecular interactions at the single bond level with a laminar flow chamber. Cell. Mol. Bioeng. 1, 247-262.

Pierres, A., Benoliel, A.-M., Touchard, D., and Bongrand, P. (2008). How cells tiptoe on adhesive surfaces before sticking. Biophys. J. 94, 4114-4122.

Pierres, A., Benoliel, A.-M., Zhu, C., and Bongrand, P. (2001). Diffusion of microspheres in shear flow near a wall: use to measure binding rates between attached molecules. Biophys. J. 81, 25-42.

Pierres, A., Feracci, H., Delmas, V., Benoliel, A.-M., Thiery, J.-P., and Bongrand, P. (1998). Experimental study of the interaction range and association rate of surface-attached cadherin 11. Proc. Natl. Acad. Sci. U.S.A. 95, 9256-9261.

Pierres, A., Tissot, O., Malissen, B., and Bongrand, P. (1994). Dynamic adhesion of CD8-positive cells to antibody-coated surfaces the initial step is independent of microfilaments and intracellular domains of cell-binding molecules. J. Cell Biol. 125, 945-953.

Pincet, F., and Husson, J. (2005). The solution to the streptavidin-biotin paradox: the influence of history on the strength of single molecular bonds. Biophys. J. 89, 4374-4381.

Rees, D. A., Lloyd, C. W., and Thom, D. (1977). Control of grip and stick in cell adhesion through lateral relationships of membrane glycoproteins. Nature 267, 124-128.

Robert, P., Benoliel, A.-M., Pierres, A., and Bongrand, P. (2007). What is the biological relevance of the specific bond properties revealed by single molecule studies ? J. Mol. Recognit. 20, 432-447.

Robert, P., Canault, M., Farnarier, C., Nurden, A., Grosdidier, C., Barlogis, V., et al. (2011). A novel leukocyte adhesion deficiency III variant: kindlin-3 deficiency results in integrin and nonintegrin-related defects in different steps of leukocyte adhesion. J. Immunol. 186, 5276-5283.

Robert, P., Limozin, L., Pierres, A., and Bongrand, P. (2009). Biomolecule association rates do not provide a complete description of bond formation. Biophys. J. 96, 4642-4650.

Rot, A., and von Andrian, U. H. (2004). Chemokines in innage and adaptive host defense: basic chemokinese grammar. Annu. Rev. Immunol. 22, 891-928.

Schenkel, A. R., Mamdouh, Z., and Muller, W. A. (2004). Locomotion of monocytes on endothelium is a critical step during extravasation. Nat. Immunol. 5, 393-400.

Schmidtke, D. W., and Diamond, S. L. (2000). Direct observation of membrane tethers formed during neutrophil attachments to platelets or P-selectin under physiological flow. J. Cell Biol. 149, 719-729.

Seifert, U. (2000). Rupture of multiple parallel molecular bonds under dynamic loading. Phys. Rev. Lett. 84, 2750-2753.

Selhuber-Unkel, C., Lopez-Garcia, M., Kessler, H., and Spatz, J. P. (2008). Cooperativity in adhesion cluster formation during initial cell adhesion. Biophys. J. 95, 5424-5431.

Shao, J.-Y., Ting-Beall, H. P., and Hochmuth, R. M. (1998). Static and dynamic lengths of neutrophil microvilli. Proc. Natl. Acad. Sci. U.S.A. 95, 6797-6802.

Solomkin, J. S., Robinson, C. T., Cave, C. M., Elmer, B., and Lentsch, A. B. (2007). Alterations in membrane cholesterol cause mobilization of lipid rafts from specific granules and prime human neutrophils for enhanced adherence-dependent oxidant production. Shock 28, 334-338.
Springer, T. A. (1994). Traffic signals for lymphocyte recirculation and leukocyte emigration: the multistep paradigm. Cell 76, 301-314.

Sundd, P., Gutierrez, E., Koltsova, E. K., Kuwano, Y., Fukuda, S., Pospieszalska, M. K., et al. (2012). «Slings »enable neutrophil rolling at high shear. Nature 488, 399-403.

Sundd, P., Gutierrez, E., Pospieszalska, M. K., Zhang, H., Groisman, A., and Ley, K. (2010). Quantitative dynamic footprinting microscopy reveals mechanisms of neutrophil rolling. Nat. Mater. 7, 821-824.

Thomas, W. E., Trintchina, E., Forero, M., Vogel, V., and Sokurenko, E. V. (2002). Bacterial adhesion to target cells enhanced by shear force. Cell 109, 913-923.

van Zanten, T. S., Cambi, A., Koopman, M., Joosten, B., Figdor, C. G., and Garcia-Parajo, M. F. (2009). Hotspots of GPI-anchored proteins and integrin nanoclusters function as nucleation sites for cell adhesion. Proc. Natl. Acad. Sci. U.S.A. 106 18557-18562.

Vitte, J., Pierres, A., Benoliel, A.-M., and Bongrand, P. (2004). Direct quantification of the modulation of interaction between cell- or surface-bound LFA-1 and ICAM-1. J. Leukoc. Biol. 76, 594-602.

von Andrian, U. H., Chambers, J. D. McEvoy, L. M., Bargatze, R. F., Arfors, K. E., and Butcher, E. C. (1991). Twostep model of leukocyte-endothelial cell interaction in inflammation: distinct roles for LECAM-1 and the leukocyte beta2 integrins in vivo. Proc. Natl. Acad. Sci. U.S.A. 88, 7538-7542.

Yago, T., Shao, B., Miner, J. J., Yao, L., Klopocki, A. G., Maeda, K., et al. (2010). E-selectin engages PSGL1 and CD44 through a common signaling pathway to induce integrin $\alpha \mathrm{L} \beta 2$-mediated slow leukocyte rolling. Blood 116, 485-494.

Yao, D.-K., and Shao, J.-Y. (2007). Flexibility of single microvilli on live neutrophils and lymphocytes. Phys. Rev. E Stat. Nonlin. Soft Matter Phys. 76, 021907.

Zaidel-Bar, R., Itzkovitz, S., Ma'ayan, A. Iyengar, R., and Geiger, B. (2007). Functional atlas of the integrin adhesome. Nat. Cell Biol. 9, 858-867.

Zeller, K. S., Idevall-Hagren, O. Stefansson, A., Velling, T., Jackson, S. P., Downward, J., et al. (2010). PI3-kinase p110a mediates b1 integrin-induced Akt activation and membrane protrusion during cell attachment and initial spreading. Cell. Signal. 22, 1838-1848.

Zhang, F., Marcus, W. D., Goyal, N. H., Selvaraj, P., Springer, T. A., and Zhu, C. (2005). Two-dimensional kinetics regulation of $\alpha \mathrm{L} \beta 2$-ICAM-1 interaction by conformational changes of the $\alpha \mathrm{L}$-inserted domain. J. Biol. Chem. 280, 42207-42218.

Zhao, Y., Chien, S., and Weinbaum, S. (2001). Dynamic contact forces on leukocyte microvilli and their penetration of the endothelial glycocalyx. Biophys. J. 80, 1124-1140.

Zhu, C., Long, M., Chesla, S. E., and Bongrand, P. (2002). Measuring receptor/ligand interaction a the single-bond level: experimental and interpretative issues. Ann. Biomed. Eng. 30, 305-314.

Zidovska, A., and Sackmann, E. (2006). Brownian motion of nucleated cell envelopes impedes adhesion. Phys. Rev. Lett. 96, 048103.

Zlotnik, A., and Yoshie, O. (2012). The chemokine superfamily revisited. Immunity 36, 705-716.

Conflict of Interest Statement: The authors declare that the research was conducted in the absence of any commercial or financial relationships that could be construed as a potential conflict of interest.

Received: 06 March 2013; paper pending published: 03 April 2013; accepted: 26 April 2013; published online: 15 May 2013.

Citation: Robert P, Touchard D, Bongrand $P$ and Pierres A (2013) Biophysical description of multiple events contributing blood leukocyte arrest on endothelium. Front. Immunol. 4:108. doi: 10.3389/fimmu.2013.00108

This article was submitted to Frontiers in Chemoattractants, a specialty of Frontiers in Immunology.

Copyright (c) 2013 Robert, Touchard, Bongrand and Pierres. This is an openaccess article distributed under the terms of the Creative Commons Attribution License, which permits use, distribution and reproduction in other forums, provided the original authors and source are credited and subject to any copyright notices concerning any third-party graphics etc. 